\title{
A ECLOSÃO DO COLONIAL EM NOSSO COTIDIANO ${ }^{1}$
}

\author{
João Pacheco de Oliveira ${ }^{2}$
}

Planejava iniciar falando diretamente sobre os processos de criminalização do ofício de antropólogo atualmente em curso para aqueles que estudam povos indígenas, seguindo de maneira estrita e obediente o tema proposto para essa mesa na programação da Semana de Antropologia da UFRN. Mas hoje na parte da manhã, dentro dessa mesma Semana, tive a oportunidade de assistir uma mesa coordenada por Juliana Melo, que me inspirou a seguir em outra direção. Percebi o quanto nossos dilemas são comuns, apesar da diversidade de objetos empíricos e das formas como pensamos resolvê-los. Entrando de chofre no meu tema mais específico, eu diria que os desafios que enfrentamos são muito maiores que a recente CPI sobre o INCRA e a FUNAI (na realidade voltada contra os antropólogos!) ou os projetos de lei que o Congresso de Eduardo Cunha e de Rodrigo Maia preparam para reformular direitos indígenas. Então, vou aqui caminhar no sentido de pensar quão grandes são os obstáculos e desafios que se levantam frente ao trabalho dos antropólogos.

Mesmo nos debates universitários persiste uma tendência - simplificadora e ingênua - de pensar isoladamente os fatos da esfera política, tomados erroneamente como sempre referidos ao Estado. Isso é ainda mais forte quando se focaliza a temática indígena, pois os seus direitos são compreendidos sempre como concessões de um soberano ou de políticas governamentais. É importante, no entanto, evitar absolutizar os tiranos de plantão e aqueles tecnocratas e administradores que colocam em prática medidas que visam destruir direitos e agredir coletividades. Sim, não tenho dúvidas de que nós devemos lutar com muita energia contra um governo ilegítimo e corrupto. Na realidade até gritamos pouco, fazemos menos mobilizações do que deveríamos. Mas por outro lado, precisamos - como cientistas e pesquisadores - refletir e aprofundar muito mais sobre o que tais manifestações efetivamente podem aportar para uma compreensão crítica de nosso país e para a reformulação de nossas práticas de pesquisa, ensino e extensão. Ou seja, precisamos ir além do ritual de protesto e da cena estritamente político-formal a que esse rito está conectado, e mergulhar no cotidiano da sociedade brasileira, compreender as suas práticas e disposições inconscientes - ainda coloniais, e nada republicanas! Fazer etnografia, testemunhar e combater a permanente produção de fronteiras, de alteridades criminalizadas. Lançar uma luz sobre essa guerra civil continuada, da qual arbitrariedades, intolerância, racismos e aumento das desigualdades são os corolários permanentes.

Nas definições do dicionário, o verbo eclodir chama atenção para algo que surge de repente, se torna visível, irrompe ou arrebenta. Entre as exemplificações, menciona sair do ovo, da casca. Eu diria que as atitudes e símbolos coloniais seriam como serpentes que saem de suas cascas. Nas formas usuais de pensar e de sentir, o colonial é visto como algo ultrapassado e irracional, sendo objeto de reprovação e censura. Porém, em contextos de forte conflito de 
interesses, ou ainda que afetam as hierarquias sociais e o sentimento de honra, tais atitudes podem definir o curso da vida social, impondo-se como uma via para resolução de problemas que aparentemente não teriam outra solução.

\section{O COLONIAL DENTRO DA NOSSA CONTEMPORANEIDADE}

Uma tentativa recente que fiz de refletir sobre isso foi o livro que eu chamei provocativamente de $O$ Nascimento do Brasil. Embora o foco dos meus estudos seja o indígena, não há ali a intenção de supor que o Brasil só possa ser pensado e compreendido unicamente na chave indígena. O que este livro aponta é que a história da nação foi escrita sem reconhecer aos indígenas qualquer significação e importância, o que é algo errado e que inviabiliza inclusive as tentativas de reinterpretá-la sem adotar uma postura crítica radical.

A escravidão indígena, ainda hoje muito pouco conhecida pelos brasileiros e quase totalmente ausente nos livros didáticos, foi um dos pilares da colonização, ao qual logo veio juntar-se a escravidão dos africanos e o tráfico negreiro. Ao longo dos séculos e de acordo com potencialidades econômicas e ambientais de cada região, diversos segmentos da população foram subalternizados, estigmatizados e excluídos de direitos.

A independência política não implicou no término da escravidão negra e a república coexistiu perfeitamente com várias modalidades de trabalho forçado. Ainda hoje, os registros de trabalho escravo no país apontam não para empresas atrasadas (supostos "resquícios" de velhas relações "feudais" ou "escravocratas"), mas para empreendimentos agroindustriais altamente lucrativos e com presença significativa no mercado internacional.

Eu queria recuperar aqui e agora um tema de grande importância. É o quanto há, na sociedade brasileira, em especial no Nordeste, de preconceituoso em relação ao "outro". É necessário logo de início fugir de generalidades e de eufemismos. Não estamos lidando com um alter, um diferente, algo que corresponde a um espelho de um ego de certo modo, mas sim de um "outro", que representa o inimigo e uma forma extremamente negativa de humanidade.

É preciso dar nomes concretos a esses "outros", que são os excluídos pela elite dirigente das modalidades mais plenas de cidadania - são os negros e indígenas, por extensão metonímica os pardos, mestiços e pobres. O Rio Grande do Norte é, por sinal, um dos estados do Brasil em que a presença indígena foi por mais largo tempo negada e excluída das suas manifestações culturais e de suas tradições intelectuais. Os indígenas foram devorados e esquecidos, assimilados aos estudos de cultura popular, como tão brilhantemente Carlos Guilherme do Valle $(1993 ; 2005)$ nos mostrou em relação ao ritual do Torém. Algo também semelhante se poderia dizer da invisibilidade dos negros no estado, igualmente verificada no Ceará e na Paraíba.

Há curiosidade em relação aos indígenas, há museus para guardar objetos arqueológicos ou de populações amazônicas, há a obra superimportante do notável Luís da Câmara Cascudo, entre outros autores a citar. Mas o que os pesquisadores e o pensamento hegemônico julgam estar tratando quando falam desse "outro", o indígena, são puramente "coisas do passado". Tal como no horizonte cognitivo e emocional do indianismo do século XIX (de que trato no cap. 2 do livro acima citado), os indígenas foram declarados como inexistentes, e tudo que com a sua vida atual se relaciona é apropriado facilmente por um discurso preconceituoso e deslegitimador. 
Necessitamos tomar isso mais a sério. A descontinuidade entre aquelas representações do fim do século XIX e a dos pesquisadores atuais é abissal, assim como as orientações da ciência e do mundo dos direitos. No entanto o senso comum continua a apelar para as concepções acadêmicas do passado e a divergir das demandas referidas aos direitos estabelecidos na Constituição de 1988. Ao constatar isso, desvela-se o quanto de atitudes racistas e preconceituosas, nada republicanas, centradas na explícita reprodução da desigualdade que ainda pesam sobre o nosso contexto universitário atual e as atividades de pesquisa e extensão de que participamos.

Falamos hoje nos debates da manhã a respeito da absoluta insensibilidade da sociedade brasileira em relação a verdadeiros processos de genocídio realizados no cotidiano. É o caso, por exemplo, dos jovens negros em favelas cariocas, que abordei no último capítulo de $O$ Nascimento do Brasil. Isso não é específico do Rio, também ocorre regularmente em São Paulo e na maioria das grandes cidades do país. As violências praticadas no dia-a-dia contra a maioria da população urbana - negra, parda ou pobre - são fatos inteiramente naturalizados pela opinião pública, enquanto a grande mídia se esmera em difundir a sensação de insegurança na classe média, estimulando a construção de estereótipos criminalizantes sobre a população das periferias. Os estrangeiros muitas vezes se chocam com isso, mas os brasileiros parecem crer que isso faz parte de um legado colonial do qual não há escapatória, que se trata da única forma de resolver problemas sociais para os quais não veem outra solução possível. Isso é terrível e muito preocupante!

Os antropólogos e outros cientistas sociais precisam ter a capacidade de mergulhar nesse passado colonial ainda absolutamente vivo e trazer à tona $\mathrm{o}$ quanto do Brasil atual é produto de uma sociedade que foi montada sob a bandeira da apropriação de territórios e de recursos naturais de "outros". Primeiro os povos indígenas, com a sua escravização e a imposição de modalidades compulsórias de trabalho; logo após com os escravos negros, prosseguindo depois com mamelucos e caborés, por fim toda a população rural. A construção de comunidades políticas e a acumulação de riquezas se deu mediante a guerra e a continuada "outrificação" de grupos e pessoas igualmente habitantes desse espaço, mas cujos direitos foram desde o início - e continuam a ser - absolutamente desconhecidos e negados. Intolerância e racismo são componentes imprescindíveis dessa forma econômica e desse modo de dominação política.

A colonialidade de que estou tratando não é apenas a crítica das teorias sociológicas eurocêntricas, um belo e importante trabalho empreendido por Aníbal Quijano e outros pensadores latino-americanos. O nosso desafio prioritário é fazer etnografia e análise das práticas sociais que embasam esse modo de organização social, cuja singularidade decorre de qualificar como criminosa toda e qualquer pessoa ou grupo social cujos interesses colidam com os interesses daqueles que controlam as posições políticas e econômicas dominantes. Os quais impõem, a ferro e fogo, padrões de uso das terras e de gestão de recursos naturais que lhes sejam mais lucrativos. Tal modo de existência política é só em aparência nacional e republicana, não deixando de lado as suas bases coloniais, alimentando o racismo e a intolerância não como vestígios arqueológicos, mas como atitudes e ideologias contemporâneas.

No Brasil, o desafio aos jovens pesquisadores não pode ser somente evitar repetir de forma mecânica as teorias eurocêntricas, para isso inspirando-se equivocadamente na glamourização do "nacional", do "latino-americano" ou mesmo do "sul", nem tão pouco na pura estetização de cosmologias indígenas. $\mathrm{O}$ desafio é refletir criticamente sobre as suas próprias categorias analíticas e a sua forma de construção de uma investigação. É fundamental um esforço metateórico de revisar as condições de produção do conhecimento, procurando 
tornar-se consciente do solo ideológico em que tais métodos e teorias foram desenvolvidos, observando e descrevendo cuidadosamente os condicionantes que os jogos de poder impuseram às ferramentas e aos trabalhos produzidos.

\section{O REGIME TUTELAR: DITADURA MILITAR, OS INDÍGENAS E OS ANTROPÓLOGOS}

Avançando mais em relação ao nosso tema, eu queria pontuar a antiguidade dessas limitações. Não seria correto não levar em conta as restrições advindas da origem social e étnica da grande maioria dos pesquisadores, que ainda hoje faz dos indígenas e afrodescendentes uma parte tão exígua de nossos estudantes (sobretudo pós-graduados) e profissionais. Cabe agregar também que a antropologia no Brasil se consolidou como disciplina universitária na década de 1970, sobretudo com a criação dos cursos de pós-graduação, e que isso ocorreu justamente dentro do período da ditadura militar (1964-1985). A Comissão Nacional de Verdade, assim como suas duplicações estaduais, pôs a nu um pouco da dimensão violenta de toda ação militar durante esses anos.

A visão idílica que Darcy Ribeiro e outros haviam construído, de que os militares, e mais especificamente Rondon e seus seguidores, tiveram um papel importante para preservar os indígenas de uma situação adversa de fronteira, revelou-se como bastante parcial. O que vemos agora, a partir dos dados colocados, é totalmente distinto. Frequentemente foram autoridades militares da própria agência indigenista, por solicitação de proprietários e grileiros, que retiraram famílias indígenas de seus antigos lugares de habitação ("tekoha"), amontoando-as em reservas pequenas. Que deslocaram grupos de indígenas de uma região para outra, de modo a liberar terras para empreendimentos econômicos. Que criaram uma instituição carcerária em Minas Gerais, a Fazenda Krenak, para punir aqueles indígenas que eram considerados pelos administradores como "rebeldes" ou "incômodos".

O abandono forçado de "terras tradicionais", o acirramento dos conflitos e do faccionalismo, a imposição de práticas repressivas e carcerárias nas reservas indígenas, tais foram algumas das consequências profundamente negativas e perversas deste indigenismo tutelar. Em um desfile militar de sete de setembro, o Dia da Pátria, realizado em Belo Horizonte, em 1973, em plena ditadura, um grupo de indígenas exibiu-se conduzindo a um outro indígena (supostamente um infrator) acorrentado a um pau de arara. Isso celebrava a maneira autoritária e truculenta de tratar com os críticos do status quo, os desviantes, os que são ditos "fora do sistema", em suma os "outros", que só merecem a tortura, o desrespeito e a violência. Essa foi a pedagogia levada pela FUNAI para as aldeias indígenas!

O que eu queria recuperar com vocês - para exorcizar - era essa visão romantizada que durante décadas a literatura antropológica (com raras exceções) passou para o público em geral sobre a atuação dos militares na questão indígena. Tal narrativa falava de uma agência estatal que protegia os indígenas, que promovia a demarcação e regularização de terras para eles, que realizava igualmente ações assistenciais específicas (educação e saúde). Na realidade o que nós vimos foi um quadro totalmente diverso, em nenhum momento houve realmente uma preocupação da agência oficial em demarcar terras de índios, em promover a fiscalização sobre essas terras, que foram (e prosseguem) extensamente invadidas. Exatamente agora, graves conflitos estão ocorrendo na Amazônia decorrentes das invasões de garimpeiros no território dos Mundurukus, Yanomami, Cinta-Larga e em vários outros povos. Por sua 
vez, as ações assistenciais desenvolvidas pela FUNAI foram inócuas e avanços só ocorreram com a transferências dessas incumbências para ministérios específicos (MEC e MS), com quadros técnicos e expertise mais adequada.

Vários dos pesquisadores aqui presentes já fizeram belas etnografias do "regime tutelar" entre os indígenas do Nordeste (caso dos Truká, com Mércia Batista; dos Potiguaras, com Glebson Vieira; dos Xucuru, com Rita Neves). Mas convém aqui, em especial dirigindo-me aos jovens, destacar a dimensão oculta e o paradoxo da tutela, pontos que focalizei nos meus estudos sobre os Ticunas. Enquanto instituição social, a tutela tem um aspecto profundamente enganoso, derivado da sua definição jurídica, que remete a uma relação que parece ser dual, unicamente estabelecida entre um protetor e um protegido. Dessa aparência decorre inclusive a sua funcionalidade, pois mascara uma relação de dominação e omite inteiramente a multiplicidade de vínculos estabelecidos entre tutor, tutelado e outros agentes sociais.

Como ferramenta analítica, a tutela precisa ser concebida como uma relação, no mínimo, triangular. Além daqueles dois elementos evidentes na relação jurídica, no vínculo contratual, existe um terceiro personagem que em geral é aquele que tem interesses naquelas terras ocupadas pelos indígenas, na sua mão de obra ou nos recursos ambientais das áreas que ocupam. As atividades desenvolvidas pela agência indigenista estiveram, através de vínculos administrativos e políticos, na maioria das vezes, em sintonia fina com esse terceiro elemento. Isto é, com um ator social que sempre se qualifica como privado, que não necessariamente ocupa postos na administração pública, mas que pode influenciar os governos para que os índios sejam cada vez mais expropriados.

Esse é um relato sucinto e esquemático dos impactos da ditadura e da tutela militar nas condições de vida dos indígenas. Mas se fizéssemos isso com a moldagem de temas e métodos de pesquisa, certamente iríamos encontrar, dentro de nossas memórias reprimidas, muitas influências diretas do regime militar sobre nossas próprias formas de realizar pesquisa. Não vou entrar em detalhes porque eu não teria condição nem tempo para isso aqui. Àqueles que tiverem curiosidade, recomendo consulta a debates filmados organizados no Centro Brasileiro de Altos Estudos (CBAE) e no PPGAS-MN em 2014, aos cinquenta anos do golpe militar de 1964. Mas se houver perguntas, posso dar detalhes de episódios sucedidos no trabalho de campo, onde realmente o pesquisador era colocado diante de toda uma estrutura piramidal de um poder repressor, no limite cristalizado no Serviço Nacional de Informações (SNI) e no Conselho de Segurança Nacional (CSN), a um pequeno passo, portanto, de ser enquadrado como um agente subversivo ou mesmo um terrorista.

O que vemos hoje, em 2017, no relatório e nos procedimentos da Comissão Parlamentar de Inquérito sobre a FUNAI e o INCRA, não é absolutamente algo novo! A FUNAI continuou militarizada até meados dos anos 1980, chegando a contar, em suas posições de direção, com a presença de doze generais ou coronéis. Isso afetou não apenas os indígenas, mas claramente as próprias condições da pesquisa, o acesso às aldeias e à interlocução com os indígenas, bem como as formas de circulação dos trabalhos antropológicos. Mas é uma pauta para investigações futuras, desenvolvidas na perspectiva da história da Antropologia no Brasil. 


\section{A NECESSIDADE DE UMA ETNOGRAFIA DAS FORMAS DE PRODUÇÃO DE CONHECIMENTO}

Eu queria explicitar alguns pressupostos de minha análise, que é derivada de alguns autores (FABIAN, FOUCAULT, BARTH E BOURDIEU), mas que resulta igualmente de vivências, experiências e elaborações próprias. Em especial, o monumental trabalho de Stocking Jr sobre a história da Antropologia, que nos impõe tomar como ponto de partida o fato de que todo conhecimento é socialmente produzido, narrado e interpretado, transmitido e utilizado. Não tem cabimento continuar a atualizar uma história idealista da ciência, fixada apenas nos conceitos e normatividades, sem buscar enraizar os cientistas em seu contexto social. Para isso é imprescindível registrar e refletir minuciosamente sobre os usos sociais que foram atribuídos a esses conhecimentos.

Essa nova abordagem deve ser praticada desde o momento inaugural e primário da pesquisa de campo, buscando transformar autores e obras em atores efetivos e em produtos de situações sociais vividas. Ou seja, compreendendo os dados e as interpretações que engendraram como resultantes de uma específica "situação etnográfica" (PACHECO DE OLIVEIRA, 2016, p. 33), a qual precisa ser desvendada e cuidadosamente analisada, pois traz uma nova luz para os conceitos e teorias formuladas, a metodologia adotada, os usos e sentidos que o trabalho poderá ter. Essa, creio, é uma ferramenta muito importante para o trabalho crítico.

Na pesquisa de campo e nas etapas seguintes, o trabalho do antropólogo é profundamente marcado pela sua inserção social e pela conjuntura política em que vive. O público ao qual ele se dirige, as instituições às quais está vinculado e as agências financiadoras que o subsidiam, bem como as perguntas e interdições colocadas pelos grupos dominantes, são fatores que também configuram o contexto de sua pesquisa, e precisam, portanto, serem descritos e considerados. Os limites da pesquisa, o que ela vê ou silencia, o que ela deve buscar e responder (ou inversamente tratar como secundário), precisam ser objeto de descrição e reflexão, pois podem manter vínculos íntimos com o exercício da etnografia e a elaboração de conceitos, métodos e teorias interpretativas.

Não basta atentar para ideologias políticas reivindicadas. Frequentemente o pesquisador assume uma postura de antagonismo ao núcleo de poder na sociedade, declarar-se de "esquerda" ou um 'radical". Isso pode ser até uma fonte fácil de prestígio para intelectuais e artistas, mas ele continuará, de qualquer modo, imerso e limitado por outras redes e jogos de poder de que não se dá conta ou que prefere não enunciar. É importante que os seus interlocutores na pesquisa, assim como os seus leitores posteriores, tenham consciência disso.

Pensando, sobretudo, nas navegações pela disciplina a serem empreendidas pelos jovens estudantes e pesquisadores, eu queria aqui, com intenção de estimular o debate, enumerar quatro formas de fazer Antropologia. Correspondem a cristalizações vivas de práticas distintas e que fizeram parte da história da disciplina. Antes foram propulsores e agora se tornaram obstáculos ao avanço da Antropologia. São metáforas (e não conceitos), visam funcionar como sinalizadores, desestimulando gostos antigos, deslegitimando hábitos estabelecidos e ainda atuantes, demarcando escolhas impensadas e apontando verdadeiros icebergs a evitar.

Me preocupa o quanto de pressupostos coloniais continua a ser reproduzido em nossos manuais e na leitura dos clássicos, transmitidos através de metáforas e categorias consagradas, mas que nos afastam de pensar a singularidade do processo de conhecimento, impondo interpretações antigas a 
experiências novas e que poderiam ter resultados fecundos. Queria destacar em especial o quanto de uma relação colonialista continua a existir na interação entre "nós" (os antropólogos) e os nossos "outros" (os indígenas, entre outros), bem como entre nós, os cientistas e autores, e o nosso público. Talvez colocar imagens caricaturais, pesadas como as que vou acionar a seguir, pode ajudar-nos a pensar se a Antropologia tal como a praticamos, em sala de aula, no campo ou na extensão universitária, move-se realmente em um universo pós-colonial.

\section{QUATRO FORMAS DE CONCEBER O "OUTRO"}

Nesta parte final, gostaria de voltar ao debate mais amplo sobre a Antropologia e as seus múltiplas formas de relação entre os antropólogos e seus "outros", isto é, como se dá de maneira plural a construção de conhecimentos em antropologia. Embora claramente inspirado e devedor de Johannes Fabian (1983), a minha preocupação não se volta para as correntes teóricas e as disputas internas à academia, mas para as relações de uso e dominação transportadas e instituídas pela própria atividade de pesquisa.

A primeira dessas formas seria a que o "outro" assume fora das suas condições reais de existência, como se pudesse ser observado e sobreviver dentro de vitrines. Mas como “o índio em vitrine?", vocês perguntarão. Notem que as vitrinas dos museus foram construídas (ou inspiradas) pelo trabalho dos primeiros antropólogos. Isso se iniciou na Inglaterra, prosseguiu pela Alemanha, passou aos Estados Unidos e atingiu as partes mais distantes do mundo. Museus foram lugares importantes para pensar a formação de nações republicanas e para mostrar a distribuição e as clivagens da expansão colonial dos séculos XIX e $\mathrm{XX}$, assim como para legitimar governos, evidenciando para o público em geral a importância de uma nova ciência, a Antropologia.

Mesmo depois de saírem dos museus, terem como cenário as salas e anfiteatros das universidades, os antropólogos continuaram a coisificar os seus "outros", redispondo-os segundo séries históricas e analíticas construídas a partir de referenciais externos. As galerias foram substituídas por teses, livros, artigos, powerpoints e vídeos, onde se anunciava ao público o índio destilado de qualquer periculosidade, leia-se iniciativa ou resistência, devassado e lógico, transformado em uma marionete de conceitos e de teorias alheias.

A antropologia metropolitana, herdeira da história natural, sempre lidou com os seus "outros" como seres mortos, desprovidos de dores e iniciativas. O que ela focaliza e nos reapresenta como seu objeto são, como nos mostrou Fabian, ficções construídas fora do seu contexto social e de seu tempo histórico. As instituições ali representadas, tal como as personagens que lá surgem, não são instituições nem pessoas reais - estas foram combatidas e destruídas pela ação colonial - mas sim aquelas que foram remontadas pelos pesquisadores e colecionadores e que vieram na sequência das ações militares de conquista.

As instituições "nativas" das quais falam os antropólogos, algumas vezes até com afetada admiração, correspondem a valores, crenças e modos de vida que foram intencionalmente destruídos, esquartejados ou domesticados pelo mundo colonial, do qual o pesquisador é parte e, durante a investigação, indiscutivelmente o beneficiário. É impossível não lembrar do exercício da biologia nos séculos XVII e XVIII, elaborando as teorias sobre a anatomia humana a partir do estudo comparativo de cadáveres, consolidando protocolos de conhecimento e princípios éticos (FOUCAULT, 1980). Para o espírito científico da época, era totalmente irrelevante indagar de quem eram aqueles corpos 
e como chegaram até os laboratórios e anfiteatros. O importante era ampliar as teorias científicas que resultavam de tais experimentos.

Também para os antropólogos tornou-se um tabu falar da relação colonial e de como concretamente foram obtidos os indicadores daqueles costumes e os adornos que caracterizavam a dignidade daquela pessoa, muitas vezes conseguidos como troféus de guerra. $\mathrm{O}$ mesmo cúmplice silêncio vai se estender ao trabalho de campo, que se torna um valor fundamental para a Antropologia do século $\mathrm{XX}$, mas que continuará a ser descrito de modo ingênuo, meramente subjetivo e por vezes até triunfalista. O que chama a atenção é unicamente a etnografia dos "outros", que os imortaliza como fora do tempo, tomando como suposto que os dados e entrevistas procedem de colaborações espontâneas, enquanto resultam de fato de constrangimentos, medo, penúria e comércio de informações características de situações de guerras ou já da pax colonial.

É muito importante reconhecer que a nossa profissão foi pautada dentro de um projeto cognitivo universalista e acentuadamente eurocêntrico de coletar objetos de cultura em muitos lugares do mundo para refletir comparativamente sobre eles. Pouco importavam as condições em que tais povos e instituições viviam, o que contava é como entrariam na história do conhecimento ocidental e seriam utilizados pelas instituições de ciência. A museologização, num primeiro momento, no ato de coleta e no desdobramento posterior da pesquisa, promoveu a descontextualização dos elementos de cultura dessas populações - o que Alban Bensa chama de efeito dé-realisant, de negação de sua realidade. Num segundo momento, na exibição contemporânea dos resultados atingidos, realiza de maneira sistemática e inconsciente uma "outrificação" de coletividades vivas e de sujeitos históricos reais, que permanecem sendo qualificados como "primitivos", "selvagens", "remanescentes". Ou seja, a representação engendrada pelos museus, a "ilusão museal" (Pacheco de Oliveira \& Santos, 2016), toma-os como se fossem "fósseis vivos".

A Antropologia, quando surge, tem suas práticas e teorias relacionadas à formação de museus e coleções. No entanto, ainda hoje, sem aplicação a objetos, mas sim a ações e eventos sociais, persiste nela uma tendência à objetificação, que isola as pessoas concretas, as dinâmicas e variações, destilando-as de seus contextos de operação, instituindo protocolos de conhecimento que negam a sua condição de sujeitos históricos. Nessa condição, os objetos da Antropologia, os "outros", são transformados em exemplificações acadêmicas de teses e teorias, sem questionamentos éticos, políticos e epistemológicos.

Uma segunda modalidade de pensar seria o laboratório. Ela está mais de acordo com nossas expectativas universitárias atuais - nós imaginamos sempre que os indígenas e os "outros" podem ser objetos de teses, livros e comunicações, servindo como marcadores de uma trajetória acadêmica individual ou de equipe. Tal linguagem é bastante adequada para explicarmos nossos trabalhos para as autoridades universitárias ou científicas - em sua maioria integradas por pessoas formadas no domínio das ciências experimentais e lógico-dedutivas, não nas ciências humanas - que os avaliam e lhes atribuem recursos e tempo de dedicação. Com nossos aparatos conceituais e metodológicos, fazemos crer que conseguiremos colocar essas populações dentro de situações que permitam uma observação rigorosa e o estabelecimento de generalizações e conclusões.

De tanto argumentarmos dessa forma e constatarmos até a sua relativa eficácia em demandas burocráticas, acabamos por acreditar nela. Esquecemos que quem está dentro e quem está fora do laboratório são exatamente da mesma escala, disputando e compartilhando interesses e valores, e que a situação de pesquisa necessariamente irá associá-los de formas múltiplas e imprevistas. Em muitos momentos durante a pesquisa de campo, é difícil saber quem é realmente 
o "eu" e o "outro", o observador e o observado, quem está de um lado e do outro do campo da observação. Os pesquisadores são observados, geram informações para os seus "nativos", que os reinterpretam todo o tempo e muitas vezes reagem contra a forma e o objetivo da investigação.

A noção de laboratório parece funcionar muito bem dentro do contexto científico atual e assim, apesar dos inconvenientes, acabamos por adotá-la em nossas unidades de pesquisa, grupos de formação e atividades de extensão. Mas há um preço - o de concebermos nossa prática de pesquisa segundo padrões inadequados e distorcidos. Por exemplo, quando um economista está observando a linha de preços ou os índices de inflação, não tem qualquer impacto no que está estudando, a sua presença é praticamente irrelevante dentro de um grande conglomerado estatístico. Não é assim a situação do pesquisador dentro das áreas indígenas, quilombolas, periferias urbanas, grupos estigmatizados, presídios, instituições governamentais ou mesmo filantrópicas. O pesquisador em Antropologia muitas vezes é uma pessoa de bastante importância na vida local do grupo que estuda, a sua simples presença pode afetar em muito os padrões de atuação daquelas pessoas. O pesquisador está sempre sendo observado!

Em certas situações, a sua conduta será copiada e poderá ser tomada como um modelo a ser seguido. Quase sempre é um mediador na relação de seus objetos de investigação com outros agentes sociais, frequentemente serve também como intermediário entre o local e outras escalas, e até algumas vezes pode ser interpretado como um mensageiro das tradições e de personagens cosmológicos. Não é raro dentro da literatura etnológica encontrar pesquisadores que foram imaginados como messias, xamãs e reencarnação de personagens míticos ou de figuras importantes do passado.

O laboratório, assim, é uma forma bastante unilateral de pensar uma relação de pesquisa, minimizando os impactos que o investigador tem naquilo que estuda, evitando problemas de responsabilidade social e de construção conjunta de comunidades políticas e de formas de cidadania. Com essa ferramenta intelectual e afetiva, o pesquisador parece delimitar claramente os seus próprios objetivos, compromissos e limites, o destino da população observada é um; e o do pesquisador, totalmente outro. Finda a pesquisa antropológica, os seus "outros" irão continuar a viver com os mesmos problemas de antes, e o pesquisador terá pela frente uma carreira acadêmica potencialmente ascendente.

Pensar a situação etnográfica como um laboratório é algo muito inadequado, pois elide questões éticas e políticas, não permite explorar e qualificar a forma de objetividade e rigor que embasa concretamente cada relação de pesquisa, estimula uma ideia simplista de não-interferência nos processos observados e separa equivocadamente os dados e suas elaborações posteriores do contexto em que está situado e as interações concretas de que resulta.

Uma terceira forma de falar sobre o "outro" seria a estetização. Os indígenas, por exemplo, dos quais falarei mais explicitamente nesta parte, foram objeto de uma construção romântica dentro do ocidente, e isso vem desde o século XVI. Foram colocados pelos filósofos como seus duplos, propondo ao ocidente formas de humanidade que existiriam sem o autoritarismo, a violência e a exploração. Foram estímulos poderosos para utopias políticas e projetos de reforma social. Se são bons para fazer pensar, estão sempre recobertos por ideias como a de atraso, inadequação ao mundo contemporâneo e um inevitável desaparecimento.

Uma inspiração romântica foi sem dúvida importante para o trabalho de campo, levando os antropólogos a explorar regiões distantes, algumas vezes ambientes inóspitos. Eram grandes desafios buscar entender as razões e sentidos 
que motivavam os indígenas reais, ao invés de repetir os preconceitos coloniais. Os antropólogos tentaram assim entender essas sociedades e culturas em seus outros termos, recusando argumentos simplistas e explicações etnocêntricas. Contribuíram dessa forma em muito para descolonizar a ciência ocidental, mostrando a diversidade e eficácia das múltiplas formas de organização social e a pluralidade de saberes, línguas e experiências que compunham os conhecimentos indígenas.

Muito raramente, porém, os antropólogos chegaram a essas populações antes de pesadas intervenções coloniais, que se refletiram em grandes perdas demográficas, deslocamentos compulsórios, situações de privação, dependência e patronagem. No Brasil, por exemplo, os casos de guerras declaradas contra povos indígenas, as chamadas "guerras justas", que vitimaram os Tupinambás, Aymorés, Caetés, Manaós, índios do Sertão do Nordeste, Muras, Botocudos, Puris, etc, antecederam a Independência.

Outras ações similares, no entanto, prosseguiram por todo o século XIX, como as de "pacificação e catequese" (implicando "descimentos" e "correrias", com destruição de malocas e a morte e escravização no vale amazônico) e a caça profissional e o extermínio por "bugreiros" (na região sul e em Mato Grosso).

A República trouxe, através de uma agência estatal específica, o SPI e depois a FUNAI, uma forma menos letal de intervenção, a chamada ação indigenista, com as "pacificações", que implicaram sedentarização, tutela e patronagem, empreendidas por militares (Rondon e seus seguidores) e, mais tarde, pelos chamados "sertanistas" (os irmãos Villas Boas, Francisco Meireles e muitos outros).

As etnografias realizadas sobre os indígenas do Brasil sempre os estudaram no "pós-pacificação", em condições de sedentarização e dependência, seja na situação histórica de "regime tutelar", com o domínio da FUNAI (em Postos e Parques Indígenas), ou de agências missionárias, seja sob a patronagem de fazendeiros, extratores e comerciantes e autoridades locais.

É um mérito indiscutível, a partir da memória contemporânea e dos depoimentos dos indígenas atuais, reconstituir essas populações enquanto sistemas autônomos de organização social e de conhecimentos, trazendo a especificidade dessa experiência para o patrimônio da ciência e da humanidade. Mas há um risco enorme em supô-las como instituições ideais e ignorar a complexidade real dessas populações, que continuam a reproduzir elementos de suas tradições e pôr em prática estratégias sociais e políticas, lançando mão inclusive de outros conhecimentos e alianças (não somente com antropólogos, mas também com indigenistas, missionários e agentes econômicos variados). A cultura, resgatada pelo pesquisador, não pode ser imposta aos indígenas de carne e osso, que não podem ser tutelados e avaliados exclusivamente por uma abstração acadêmica, mas têm - como qualquer população do planeta - seus próprios horizontes e suas estratégias políticas.

É comum que as pessoas se encantem ao ver certas exposições, vídeos, documentários sobre os indígenas que exibem as tradições nativas como referenciais únicos. O antropólogo, no entanto, deve se perguntar: isso corresponde a algum indígena real, algum projeto político existente dentro dessas populações? E frequentemente a resposta é negativa. Ao observar a situação dentro das aldeias, fazer uma visita, por exemplo, a áreas distantes da Amazônia, nos limites com Bolívia, Peru, Colômbia, Venezuela e Guiana Inglesa, o que se encontra é algo completamente diferente. Estão implantadas nessas áreas indígenas formas extremas de violências, submissão às populações envolventes e 
agentes externos (como madeireiras, mineradoras etc), inclusive com a ação de grupos armados, contrabandistas e narcotraficantes. Em muitos casos, é o próprio órgão tutelar ou missionários que subalternizam e reprimem tais populações. Por outro lado, os conflitos internos revelam-se de grande intensidade, envolvendo disputas entre famílias, gênero, geração, opções religiosas. Relatos muito próximos às periferias urbanas podem ser feitos sobre indígenas que habitam no interior do Amazonas, a mais de mil km de Manaus.

O indígena estetizado que vemos em alguns grandes museus, que são celebrados em exposições no Grand Palais de Paris, é um produto construído por antropólogos, museólogos, colecionadores e estudiosos de arte primitiva. Esses profissionais têm um mérito, como o artista também, de produzir uma bela obra que possa emocionar o público urbano e atrair turistas de todas as partes do mundo. Mas aquela obra é uma ficção, uma construção que remete ao artista e de maneira alguma ao próprio pesquisado, nem à sua realidade vivida.

Há que mencionar, por fim, uma outra categoria, que é o mercado, que se infiltra e reenquadra algumas das práticas que derivam das metáforas precedentes. Os conhecimentos e imagens sobre os "outros" engendradas durante o processo de pesquisa também podem ser transformados em bens e produtos de mercado, gerando retornos como qualquer outra mercadoria. $\mathrm{O}$ mercado de consultorias é um grande escoadouro para jovens pesquisadores que não são absorvidos na estrutura universitária de ensino e pesquisa, operando em relação à produção de conhecimentos com regras próprias e frequentemente discrepantes da comunidade científica (vide livro e documento produzido pela ABA sobre perícias antropológicas - 2014 e 2016).

Também não é raro que, para obter financiamentos, equipes de pesquisa tenham de metamorfosear suas propostas de investigação em prioridades estabelecidas por governos e instituições internacionais, podendo assim acessar fundos e programas especiais de fomento a certos temas de pesquisa.

Sendo empurrados com tamanha força nessa direção, não é de surpreender que os próprios estudantes e pesquisadores comecem de modo não consciente a adequar os seus objetos de investigação com posturas e critérios impostos pelo mercado, e não pelos cânones da Antropologia. Frequentemente você vê pesquisadores sendo apresentados como "especialistas", o que supostamente lhes autorizaria a falar e escrever com liberdade sobre povos indígenas, recebendo disso todas as benesses possíveis e transformando-se em detentores de um conhecimento único, comercializável por empresas privadas e apossado por governos. Mas é função do conhecimento antropológico vir a substituir a manifestação concreta de vontade dos indígenas, anulando-os enquanto sujeitos políticos? Não é desrespeitoso e unilateral fazer supor que o seu futuro está inscrito em seu passado e pode ser lido com exatidão pela nova casta de leitores de mãos e cartomantes em que o mercado transforma os aprendizes afoitos de uma ciência ainda mal purgada dos pressupostos do colonialismo? A ideia de um "especialista" sobre algum povo indígena é estratégia política de uma perversidade absoluta, com efeitos igualmente deletérios sobre o processo de conhecimento e os próprios rumos da disciplina.

Certamente os professores aqui presentes têm a experiência de, em comissões de avaliação, ler inúmeros projetos de pesquisa. Muitos nos deixam com a incômoda sensação de que o autor parece estar evoluindo pelas prateleiras de um supermercado, comparando produtos e preços, como se estivesse escolhendo um objeto que ele pode comprar e levar para casa, declarar então como seu e dali tirar futuros ganhos e prazer. Para uma disciplina como a Antropologia, cuja experiência de pesquisa frequentemente se realiza dentro das casas dos pesquisados, acessando suas memórias e arquivos, compartilhando narrativas 
e sensações bastante íntimas, tudo isso é muito invasivo e preocupante. Se o pesquisador se imagina como tão descolado da situação concreta que vivencia e investiga como então pretender, senão como retórica ou simulação, "transformar o exótico em familiar” ou buscar algo como uma "fusão de horizontes”?

\section{CONSIDERAÇÕES FINAIS}

Eu arrolei essas formas de conceber e falar sobre os indígenas como um estímulo para que procedamos a uma catarse em relação às nossas práticas e representações cotidianas, apontando a presença de atitudes e imagens coloniais não apenas na vida brasileira contemporânea, mas também em nosso cotidiano de pesquisa. Certamente, na maioria dos contextos acadêmicos, repudiamos com energia essas quatro formas de pensar o indígena. Mas no momento em que explicamos as nossas atividades de pesquisa para colegas de outras disciplinas, profissionais liberais, autoridades e mesmo nossos amigos e parentes, será que aquelas imagens não afluem com muita força? E será que, em momentos de informalidade, em que - professores e estudantes - fazemos pilhérias com os nossos desejos e limitações, não patinamos igualmente naquelas antiquadas ideias?

Espero que esta fala enseje uma boa e útil polêmica. Reitero que sem um esforço de descolonização muito ativo dos nossos instrumentos, dos usos concretos que damos a teorias e métodos, como tentei fazer em outras ocasiões, não conseguiremos produzir avanços maiores em nossa própria disciplina. Tão-pouco seremos capazes de lidar com o desafio de estudar a eclosão do colonial no mundo contemporâneo, de fazer etnografia e refletir sobre os processos reais de dominação, outrificação, violência e criminalização da maioria da população.

Não serão as citações consagradoras do estruturalismo, do interpretativismo ou de muitos outros "ismos" que nos podem fazer avançar. O que nos pode libertar é ter uma consciência crítica em relação à nossa prática investigativa. A questão crucial é enfrentar o caráter dialógico e histórico da produção de conhecimento.

\section{NOTAS}

${ }^{1}$ Transcrição da Conferência de João Pacheco de Oliveira na Semana de Antropologia UFRN 2017, realizada por Cristina Diógenes Souza Bezerra, revisada por Angela Facundo e pelo autor.

${ }^{2}$ Antropólogo e Professor Titular da Universidade Federal do Rio de Janeiro/UFRJ. Fez pesquisa de campo prolongada com os índios Tikuna, do Alto Solimões (Amazônia), da qual resultou sua dissertação de mestrado (UNB, 1977) e sua tese de doutoramento (PPGAS, 1986), publicada em 1988. Realizou também pesquisas sobre políticas públicas, coordenando um amplo projeto de monitoramento das terras indígenas no Brasil (1986-1994), com apoio da Fundação Ford, projeto que resultou em muitos trabalhos analíticos, coletâneas e atlas. Orientou mais de 60 teses e dissertações no Programa de Pós-Graduação em Antropologia Social (PPGAS), voltadas sobretudo para povos indígenas da Amazônia e do Nordeste, em programa comparativo de pesquisas em etnicidade e território apoiado pelo CNPq e FINEP. Atuou como professor-visitante em alguns centros de pós-graduação e pesquisa no Brasil (UNICAMP, UFPE, UFBA, UFAM e Fundação Joaquim Nabuco) e no exterior (Universidad Nacional de La Plata/Argentina, Università di Roma La Sapienza, École des Hautes Études en Sciences Sociales/ Paris, Universidad Nacional de San Martin/UNSAM/Buenos Aires e Institute des Hautes Études de l'Amérique Latine/IHEAL/Sorbonne Nouvelle/Paris 3). É pesquisador $1 \mathrm{~A}$ do Conselho Nacional de Pesquisas/CNPq e bolsista FAPERJ do Programa Cien- 
tista do Nosso Estado. Foi presidente da Associação Brasileira de Antropologia/ABA (1994/1996) e por diversas vezes coordenador da Comissão de Assuntos Indígenas. Nos últimos anos vem se dedicando ao estudo de questões ligadas a antropologia do colonialismo e a antropologia histórica, desenvolvendo trabalhos relacionados ao processo de formação nacional, a historiografia, bem como a museus e coleções etnográficas. É curador das coleções etnológicas do Museu Nacional e organizou a exposição "Os Primeiros Brasileiros", relativa aos indígenas do nordeste, exibida em Recife, Fortaleza e Rio de Janeiro e em Córdoba, Argentina. Junto com lideranças indígenas foi um dos fundadores do Maguta: Centro de Documentação e Pesquisa do Alto Solimões, sediado em Benjamin Constant (AM), que deu origem ao Museu Maguta, administrado hoje diretamente pelo movimento indígena

${ }^{3}$ Houaiss, Antonio - Mini Houaiss - Dicionário da Língua Portuguesa. São Paulo, Editora Objetiva, 2001.

${ }^{4}$ Pacheco de Oliveira, J. - O Nascimento do Brasil e outros ensaios. 'Pacifificação', regime tutelar e formação de alteridades. Rio de Janeiro, Contra Capa, 2016. Cabe esclarecer que esta referência não é de teor comercial, está disponível em: $<$ http://jpoantropologia.com.br/pt/>. Como todos os meus trabalhos, pode, portanto, ser acessado e baixado até por celulares (muito usados pelos estudantes para pesquisas), também está acessível em meu Facebook.

${ }^{5}$ Valle, Carlos G. O. do. Terra, tradição e etnicidade: os Tremembé do Ceará. Dissertação de mestrado (Antropologia Social). PPGAS/Museu Nacional/UFRJ, 1993; Valle, Carlos G. O. do. "Compreendendo a dança do torém: visões de folclore, ritual e tradição entre os Tremembé do Ceará”. Revista Anthropológicas, ano 9, vol. 16 (2), pp. 187-228, 2005.

${ }^{6}$ Vide Benites, Tonico. Rojeroky hina ha roike jevy tekohape (Rezando e lutando): o movimento histórico do Aty Guasu dos Ava Kaiowa e dos Ava Guarani pela recuperação de seus tekoha. Tese de doutorado (Antropologia Social). PPGAS/Museu Nacional/ UFRJ. 2014.

${ }^{7}$ Vide Correia, José Gabriel Silveira, A ordem a se preservar: a gestão dos índios no reformatório agrícola indígena krenak. Dissertação de mestrado (Antropologia Social) PPGAS/Museu Nacional/UFRJ, 2000.

${ }^{8}$ Para uma visão crítica da história do SPI, vide Souza Lima, A. C. - Um grande cerco de paz. São Paulo/Petrópolis, ANPOCS/Vozes, 1994.

${ }^{9}$ Vide Pacheco de Oliveira, J. - 'O nosso governo': Os Ticunas e o regime tutelar, São Paulo/Brasília, Marco Zero/CNPq, 1988.

${ }^{10}$ V. de Pacheco de Oliveira, J. - "La situación etnográfica como uma tríada". Boletin de Antropologia, V. 20, n. 37:51-80. Universidad cde Antioquia, Medellin, Colombia. 2006.

${ }^{11}$ Para um aprofundamento, vide Valente, R. - Os fuzis e as flechas. História de sangue e resistência indígena na ditadura. São Paulo, Companhia das Letras, 2017.

${ }^{12}$ Entre outros, vide Stocking Jr, G. W. Race, culture, and evolution: essays in the history of Anthropology. Chicago The University of Chicago Press, 1968; The shaping of American Anthropology, 1883-1911. Chicago: The University of Chicago Press, 1974; Functionalism historicized: Essays on British social anthropology. Madison: The University of Wisconsin Press, 1984;

Observers observed: essays on ethnographic field work. Madison: The University of Wisconsin Press, 1984; Colonial situations: essays on the production of anthropological knowledge. Madison: The University of Wisconsin Press, 1988; Volkgeist as method and ethic: essays on boasian ethnography and the German anthropological tradition. Madison: The University of Wisconsin Press, 1996; Unfinished business: Robert Gelstom Armstrong, the Federal Bureau of Investigation, and the history of Anthropology in Chicago and at Nigeria. In: HANDLER, Richard (ed.). Central sites, peripheral visions: cultural and institutional crossings in the history of anthropology. Madison: University of Wisconsin Press, 2006. p. 99-247.

${ }^{13}$ Vide Pels, P.; Salemink, O. - Colonial subjects: essays on the practical history of anthropology. Ann Arbor: University of Michigan Press, 1999.

${ }^{14}$ No sentido usado por Bachelard, G. - La formation de l'esprit scientifique. Paris, J. Vrin, 1971.

${ }^{15}$ Vide Fabian, J. - O tempo e o outro. Como a antropologia estabelece seu objeto. 
Petrópolis, Vozes, 2013; e Anthropology with an atitude. Critical essays.Stanford, Stanford University Press, 2001.

${ }^{16}$ Vide Foucault, Michel. O Nascimento da Clínica. Rio de Janeiro: Forense Universitária, 1980.

${ }^{17}$ Pacheco de Oliveira, J. e Santos, R. C. M - "Descolonizando a ilusão museal: etnografia de uma proposta expositiva". Museus e atores sociais. Perspectivas antropológicas. Lima Filho, M.; Abreu, R.; Athias, R. Recife, Editora UFPE. 2016. (pág. 125-155).

${ }^{18}$ Pacheco de Oliveira, João; Mura, Fábio; Barbosa, Alexandra. (Org.). Laudos Antropológicos em perspectiva. Brasília, DF: ABA, 2015. 